\title{
El Buen Vivir como alternativa al desarrollo y su relación con la Soberanía Alimentaria. El caso ecuatoriano
}

Xavier León*

Resumen

En este artículo Se pretende analizar el concepto de BUen ViVir y SU Relación con la Soberanía Alimentaria. EN UN PRIMER MOMENTO HACEMOS UN RECUENTO DE LOS ORÍGENES Y EL CONCEPTO COMO TAL DEL BUEN VIVIR; Y SU

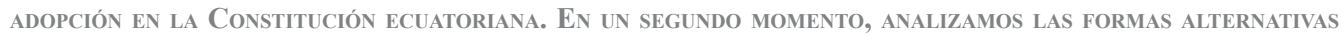

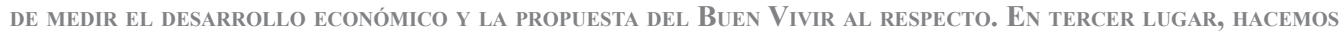

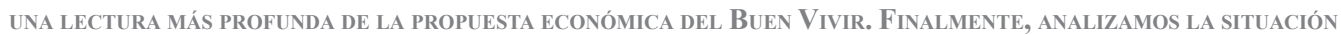

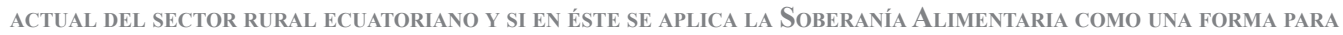
aLCANZar El Buen ViVIR.

Palabras claves: Buen Vivir - Sumak Kawsay - Soberanía Alimentaria - Alimentación - Desarrollo Rural.

\section{Abstract}

This article aims to analyze the CONCEPT OF BUEN VIVIR AND ITS Relationship With Food SOVEREIGNTy. First, WE PRESENT AN OVERVIEW OF THE ORIGINS AND CONCEPTION OF BUEN VIVIR AS SUCH, AND ITS ADOPTION INTO THE

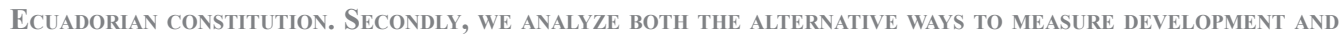
THE CORRESPONDING PROPOSAL OF BUEN VIVIR. THIRDLY, WE EXAMINE MORE DEEPLY BUEN VIVIR'S ECONOMIC PREMISE.

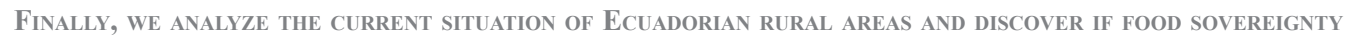
HAS BEEN APPLIED IN THESE AREAS AS A WAY TO ACHIEVE BUEN VIVIR.

Keywords: BUen Vivir - Sumak KaWSAY - FOOd SOVEREIGNTY - NUTRITION - RURAL DEVELOPMENT.

* Investigador sobre temas de Soberanía Alimentaria, miembro de Acción Ecológica, Doctorando en Estudios del Desarrollo / Universidad del País Vasco - Instituto HEGOA. Correo electrónico: xavierobjetor@gmail.com. 


\section{Introducción}

71 Buen Vivir, Suma Qamaña en Aymara, o Sumak Kawsay como se lo denomina en la cosmovisión kichwa, es un concepto que ha emergido recientemente en las discusiones sociales y académicas, sobre todo en los países andinos de Bolivia y Ecuador. El Buen Vivir es visto como un concepto alternativo al concepto de desarrollo actual, que está caracterizado por una fuerte presencia del capital, como una forma de medir el progreso de una sociedad.

Sin embargo, esta visión economicista clásica de ver el desarrollo ha demostrado ser insuficiente para medir la calidad de vida de un pueblo y su real progreso en torno a otros factores fundamentales, tales como los derechos garantizados, que pueden dar una idea más global del grado de bienestar de un ciudadano en su país o territorio, y como a través de estos se contribuye a tener una vida buena en armonía con la naturaleza.

En este artículo se pretende analizar el concepto de Buen Vivir, partiendo de la pregunta de si ¿La adopción a nivel constitucional del paradigma del Buen Vivir por parte del Ecuador, ha contribuido al mejoramiento de las condiciones de vida sobre todo de los pobladores rurales?

Para esto, en un primer momento veremos los orígenes y el concepto del Buen Vivir y su adopción en la Constitución ecuatoriana; en un segundo momento analizaremos las formas alternativas de medir el desarrollo, así como la propuesta del Buen Vivir al respecto; en tercer lugar se profundizara en la propuesta económica del Buen Vivir; y, finalmente, analizaremos la situación actual del sector rural ecuatoriano y si se ha logrado aplicar la Soberanía Alimentaria como una forma de alcanzar el Buen Vivir.

\section{El surgimiento del Buen Vivir como una alternativa de desarrollo}

Los orígenes del concepto de Buen Vivir, viene de los pueblos y nacionalidades indígenas, que lo propusieron, sobre todo a partir de las acciones de la década de 1990 a raíz de los eventos de los 500 años de conquista española. Surge como un aporte y alternativa al modelo actual de desarrollo (Tortosa, 2011). En este sentido tiene similitud con otros conceptos emergidos de los movimientos sociales, como el de Soberanía Alimentaria ${ }^{1}$ desde la Vía Campesina.

El Buen Vivir ha sido conceptualizado de diversas maneras, tanto en los discursos sociales, como en los discursos jurídicos para reconocimiento de derechos. Podemos mencionar al respecto los trabajos de Acosta (2010), Tortosa (2011), Acosta y Martínez (2009), entre otros.

Basados en los autores anteriores podríamos definir al Buen Vivir como una alternativa al desarrollo, que plantea en el marco de una filosofía colectiva, el vivir en una sociedad que se desarrolle promoviendo un alimentación sana basada en la Soberanía Alimentaria, educación que respete los saberes ancestrales, salud que incluya a todas las personas con acceso a derechos que contribuyan a mejorar la calidad de vida, así como la conservación de los recursos y territorios para las generaciones futuras, entre otros factores que ayuden a mejorar el bienestar de las personas en armonía con la naturaleza.

La idea de vivir bien y en armonía, es una de las premisas fundamentales tomadas de la cosmovisión indígena Kichwa en el Ecuador y que tiene en común con otras cosmovisiones andinas de la región como el caso de los Aymaras en Bolivia.

Para Acosta (2010), el plasmar este concepto como un derecho en la Constitución ecuatoriana efectivamente respondió a las luchas campesinas, indígenas, de jóvenes y otros actores que confluyeron en la idea del Buen Vivir como una alternativa de desarrollo al modelo actual.

1 El concepto de Soberanía Alimentaria, surgió a mediados de los años 90, como una alternativa al modelo actual de producción de alimentos. 
El Buen Vivir como alternativa de desarrollo se incluyó en la Constitución del Ecuador como una serie de derechos a ser garantizados por el Estado, así como acciones en el marco del régimen de desarrollo (ver Tabla 1), que en conjunto crean las condiciones para la consecución del Buen Vivir de los ciudadanos del país (Gudynas y Acosta, 2011).

TABLA 1. Derechos enmarcados en el Buen ViVIR en la Constitución del Ecuador

\begin{tabular}{|l|c|}
\hline Derechos & Artículo \\
\hline Agua y alimentación & 12 y 13 \\
\hline Ambiente sano & 14 y 15 \\
\hline Comunicación e información & 16 al 20 \\
\hline Cultura y Ciencia & 21 al 25 \\
\hline Educación & 26 al 29 \\
\hline Hábitat y vivienda & 30 al 31 \\
\hline Salud & 32 \\
\hline Trabajo y seguridad social & 33 al 34 \\
\hline
\end{tabular}

Fuente: Constitución del Ecuador (2008).

Estos derechos desde la perspectiva de la Constitución ecuatoriana, son las cuestiones que se deben cumplir para lograr un desarrollo basado en el Buen Vivir. Adicionando a estos la Soberanía Alimentaria, los derechos de la naturaleza, soberanía económica y energética, así como las acciones enmarcadas dentro del régimen de desarrollo contemplados en los artículos 275-278 de la Constitución, como ejes para lograr el desarrollo.

Sin embargo, varios autores ${ }^{2}$ concluyen con razón, que el Buen Vivir no debe limitarse tan solo a la garantía de derechos y políticas en torno al régimen de desarrollo para lograrlo. La discusión sobre qué se entiende por Buen Vivir va de lado por enmarcarlo como una filosofía de vida caracterizada por el bien común y una adecuada calidad de vida de todos y todas.

Por otro lado, la incorporación de los derechos de la naturaleza en el caso ecuatoriano, es una de los principales reconocimientos al paradigma del Buen Vivir, donde por primera vez se reconoce a la naturaleza como un sujeto de derechos en los artículos 71 al 74 de la Constitución. En estos artículos entre otras cosas se menciona la importancia de generar respeto y defensa de la naturaleza, así como el adecuado establecimiento de medidas de restauración de la naturaleza para el alcance del Buen Vivir. Esta nueva forma de asumir a la naturaleza plantea un cambio, al no verla simplemente como una fuente de extracción de recursos y depósito de desechos para beneficio del capital (Martínez, 2011), proponiendo que solo con una relación simbiótica y respetuosa con la misma se podrá lograr Buen Vivir.

Entre los principales aportes del Buen Vivir, como una alternativa al desarrollo en el contexto actual, se cuentan la relación del ser humano con la naturaleza; el cuestionamiento del concepto de pobreza entendida ésta como carencia de bienes o el de riqueza como abundancia, cuestionando así el concepto occidental del progreso (Acosta, 2010).

Para Acosta (2010), por ejemplo, el Buen Vivir también debe ser visto como una alternativa al modelo de desarrollo actual, caracterizado por la supremacía del capital sobre el bien común de las personas. En este sentido la visión de Acosta, el cual ha sido uno de los principales impulsores de este concepto tanto a nivel Constitucional, académico y social, es que el buen

2 Tortosa (2009); Acosta (2010); y Gudynas (2011), coinciden en sus análisis en que el buen vivir debe trascender más allá de la sola garantía de derechos y debe incorporar una serie de acciones que permitan ver a esta visión como una real alternativa al desarrollo. 
vivir debe ser visto como un concepto en construcción y en evolución constante que conforme se vaya profundizando irá abarcando más aspectos en torno a la forma de ver el mundo y mejorar las condiciones colectivas.

El Buen Vivir desde su origen en la cosmovisión indígena, aporta una forma diferente de ver al mundo y los seres humanos, una forma de atender las necesidades de los mismos desde otra perspectiva que se centre en el vivir en armonía y con lo necesario para ser feliz con respeto a la naturaleza y los territorios de las colectividades. Desde esa visión el Buen Vivir es un proceso que aporta soluciones desde los pueblos originarios a los problemas creados por el mundo occidental (Tortosa, 2009).

Por otro lado, existen varios autores que critican la idea de Sumak Kawsay, al considerarlo un término "inventado" y surgido recientemente. Una idea que no se ha discutido anteriormente en el mundo indígena (Sánchez Parga, 2011; Recansens, 2014; Stefaoni, 2011). Frente a esto, los defensores del Sumak Kawsay o Buen Vivir, mencionan que, si bien es cierto, el término Sumak Kawsay surge recientemente en los textos académicos, con autores como Viteri (2003), esto no significa que este término no haya existido anteriormente (Hidalgo et al., 2014). Pues, hay que entender que la idea de Sumak Kawsay de los pueblos indígenas, es un término que se ha venido construyendo y que partió de algunos principios de la cosmovisión indígena, enriqueciéndose con los aportes de varios sectores sociales y académicos, que lo han visto como una alternativa real a las teorías del desarrollo actual.

El Buen Vivir es una idea alternativa que, contrariamente a otras formas de ver el progreso y el llamado desarrollo, ha sido promovido desde las bases sociales de grupos organizados que proponen esta visión como una alternativa a ser tomada en cuenta por los demás ciudadanos e instituciones estatales. Lo cual podría ser una diferencia fundamental en comparación con otras visiones y modelos de desarrollo aplicados en Latinoamérica, sobre todo con aquellos aplicados en las últimas décadas, que todavía no han logrado mejorar las condiciones de vida básicas.

\section{El reto de poder evaluar y medir adecuadamente el Buen Vivir.}

El aumento de ingresos de los Estados a través del PIB, el nivel de industrialización de los países son, entre otros, algunos de los factores más importantes para medir el desarrollo en la actualidad. Priorizando de esta manera, las mediciones económicas sobre las sociales. En contraposición, varias instituciones, Estados y organizaciones han creado formas alternativas de medir el desarrollo, tratando de incorporar elementos que aporten un entendimiento más amplio, de cómo una persona puede estar viviendo en una sociedad que está desarrollándose en torno al mejoramiento de las condiciones de vida de las personas y no del capital.

Las Naciones Unidas por ejemplo, han implementado una forma alternativa de medir el desarrollo basándose en el Índice de Desarrollo Humano (IDH), que está basado en 3 dimensiones: salud, educación e ingresos; incorporando en los últimos años la desigualdad como un factor de análisis transversal (UNDP, 2013). Sin embargo esta forma de medir el desarrollo desde la perspectiva de los defensores del Buen Vivir, sigue siendo insuficiente ya que los indicadores que usa son tradicionales y no incorpora otros que deberían ser contemplados para medir la calidad de vida y el desarrollo de las personas, tales como el medio ambiente, el territorio, la vivienda, la cultura, la alimentación, entre otros.

El IDH tiene también como debilidad que el indicador de ingresos sea uno de los que más influencia tiene a la hora de analizarlo, esto hace que la explicación de los otros indicadores sea vista como insuficiente frente a este indicador (Phelan, 2011).

Algunas formas alternativas del medir el desarrollo, han ido probándose con mayor o menor éxito. Bután por ejemplo propone el Índice de Felicidad Bruta, como una forma de medir el desarrollo en esta nación, ya que bajo los indicadores tradicionales quedaba como una nación pobre, situación que según sus gobernantes no reflejaba la realidad. A través de este 
índice se evalúan cuestiones como, el bienestar psicológico, salud, uso del tiempo, comunidad, diversidad cultural, educación, diversidad medio ambiental, nivel de vida y gobierno (Phelan et al., 2012: 182).

Actualmente, incluso se habla sobre el Índice de Felicidad Planetaria ${ }^{3}$ (HPI por sus siglas en inglés), como otra forma de medir el desarrollo de los países. Este índice fue desarrollado por la New Economics Foundation. A través de este se mide aspectos como satisfacción de vida, esperanza de vida, años de vida feliz y huella ecológica. Lo interesante de este índice es que incorpora el componente ambiental y los daños que se causan a la naturaleza para lograr desarrollo, lo cual lo destaca sobre el IDH.

Podemos mencionar otros índices que intentaron medir alternativamente el desarrollo, como: el Índice de Progreso Genuino (IPG), el Índice de Calidad de Vida Física (ICFV), el Índice de Bienestar Social (IBS), Índice de Capacidades Básicas (ICB), Índice de Prosperidad, entre otros (Phelan et al., 2012). Todos estos índices, surgen frente a la necesidad de poder medir de una manera diferente el bienestar, tratando de integrar aspectos necesarios para mejorar la vida de las personas que no han sido incluidos en los índices clásicos de desarrollo.

En el caso ecuatoriano los indicadores del Buen Vivir se han elaborado en una propuesta reciente por parte del Instituto Nacional de Estadísticas y Censos (INEC), el cual consiste en el Índice de Pobreza Multidimensional (IPM), como una forma para medir los avances en materia de BV. Entendiendo la pobreza "como la falta de realización de los derechos o libertades asociados a la concepción del Buen Vivir". (Correa, 2016: 13). Según esta definición del presidente de la república, se propone evaluar el Buen Vivir desde una perspectiva de derechos garantizados y su real acceso por parte de los ciudadanos.

El IPM propone contar con 12 indicadores divididos en cuatro dimensiones: 1. educación, 2. trabajo y seguridad social, 3. salud agua y alimentación; y 4. hábitat, vivienda y ambiente sano.

\begin{tabular}{|c|c|c|c|}
\hline Dimensión & Pesos & Indicador & $\begin{array}{c}\text { Población } \\
\text { aplicable }\end{array}$ \\
\hline \multirow{3}{*}{$\begin{array}{c}\text { Educación } \\
(25 \%)\end{array}$} & $8.3 \%$ & 1. Inasistencia a educación básica y bachillerato. & 5 a 17 años \\
\hline & $8.3 \%$ & 2. No acceso a educación superior por razones económicas. & 18 a 29 años \\
\hline & $8.3 \%$ & 3. Logro educativo incompleto. & 18 a 64 años \\
\hline \multirow{3}{*}{$\begin{array}{l}\text { Trabajo y } \\
\text { Seguridad } \\
\text { social } \\
(25 \%)\end{array}$} & $8.3 \%$ & 4. Empleo infantil y adolescente. & 5 a 17 años \\
\hline & $8.3 \%$ & 5. Desempleo o empleo inadecuado & 18 años y más \\
\hline & $8.3 \%$ & 6. No contribución al sistema de pensiones. & 15 años y más \\
\hline \multirow{2}{*}{$\begin{array}{c}\text { Salud, Agua y } \\
\text { Alimentación } \\
(25 \%)\end{array}$} & $12.5 \%$ & 7. Pobreza extrema por ingresos. & Toda población \\
\hline & $12.5 \%$ & 8. Sin servicio agua por red pública. & Toda población \\
\hline \multirow{4}{*}{$\begin{array}{l}\text { Hábitat, } \\
\text { Vivienda y } \\
\text { Ambiente } \\
\text { sano } \\
(25 \%)\end{array}$} & $6.25 \%$ & 9. Hacinamiento. & Toda población \\
\hline & $6.25 \%$ & 10. Déficit habitacional. & Toda población \\
\hline & $6.25 \%$ & 11. Sin saneamiento de excretas. & Toda población \\
\hline & $6.25 \%$ & 12. Sin servicio de recolección de basura. & Toda población \\
\hline
\end{tabular}

Fuente: Castillo y Jácome (2016).

3 Más información sobre este índice se pueden encontrar en: http://www.happyplanetindex.org/about/ 
Como vemos en la tabla anterior, el Estado ecuatoriano después de casi ocho años de aprobada la Constitución, basada en el desarrollo bajo el paradigma del Buen Vivir, nos empieza a mostrar una forma de evaluar su consecución con este esquema de indicadores. Los cuales toman elementos que se miden en otros indicadores como el IDH y que incluyen aspectos como salud, educación e ingresos, adicionando otros que no se contemplan en este y otros índices.

Sin embargo, analizando más a detalle las dimensiones propuestas en el IPM, se puede observar que existen en primer lugar algunos derechos que forman parte del régimen del Buen Vivir que no se han incluido en esta propuesta. Como los que tienen que ver con comunicación e información, cultura y ciencia, que también son parte de los derechos del Buen Vivir de acuerdo a la Constitución del Ecuador.

Por otro lado en cuanto a los indicadores en sí, preocupa que en algunos casos sean muy generales y no puedan medir adecuadamente los obstáculos que se tienen para alcanzar el Buen Vivir en el país. Por ejemplo en la dimensión de salud, agua y alimentación solo se contemplan dos indicadores que son, la pobreza extrema y el acceso al agua de la red pública, dejando de lado temas tan importantes en esta dimensión, como la Soberanía Alimentaria, el acceso al agua de riego en las áreas rurales, o la disponibilidad de alimentos que provengan de la agricultura campesina en las ciudades; así como, el acceso a la salud, entre otros factores que se contemplan en la Constitución como necesarios para el Buen Vivir.

Igualmente en la dimensión de hábitat, vivienda y ambiente sano, el tema ambiental ligado a los derechos de la naturaleza no se contempla. Sobre todo ahora que este aspecto es uno de los que más preocupa a nivel territorial, por los efectos que están provocando las actividades extractivas en las comunidades indígenas y campesinas, especialmente.

Hay que tomar en cuenta que justamente el IPM, aparece en un contexto en que el gobierno actual está tratando de demostrar que el país no está en crisis, pese a las críticas de varios sectores que consideran lo contrario. Por lo que el IPM, parece más una herramienta política del gobierno que un índice que abarque todos los derechos propuestos por la Constitución para el Buen Vivir.

El Buen Vivir ya ha sido reconocido en la Constitución desde hace 8 años, sin embargo, todavía están pendientes inclusiones importantes en los indicadores a ser utilizados para poder ver los progresos que tendría un Estado o comunidad para lograrlo, y cuáles son los aspectos que estos deberían mejorar para llegar a la meta de un adecuado desarrollo para los ciudadanos. Esto es probablemente una de las principales debilidades de la propuesta de Buen Vivir, que al no contar con indicadores consensuados, no puede presentar y evaluar progresos claros en el bienestar de las personas producto de la aplicación de este modelo alternativo.

\section{Buen Vivir desde la perspectiva económica y sus obstáculos en el Ecuador}

Desde la perspectiva económica el concepto de Buen Vivir propone varios aspectos, que no pasan por las formas tradicionales de medir el desarrollo como hasta la actualidad han sido el PIB y los ingresos de las personas en salarios, así como la medición de la pobreza como un sinónimo de falta de ingresos.

La actual estructura económica actual genera formas de ver el progreso medido por la capacidad de consumo que tienen las personas de bienes producidos por el capital (Acosta, 2010), sin tomar en cuenta a sociedades o comunidades, que construyen una economía solidaria ${ }^{4}$ y tienen acceso a otro tipo de bienes comunes que les permiten gozar de una adecuada calidad de vida. Esto lo podemos ver por ejemplo en comunidades indígenas y rurales, donde el grado de autosuficiencia y de disminución de la dependencia externa en lo económico y social les provee de elementos para realizarse y crecer colectivamente.

Uno de los aspectos que autores como Acosta (2010), critican del crecimiento económico actual, especialmente en el caso ecuatoriano, es basarlo en la extracción de recursos naturales

4 No está basada en los ingresos monetarios. 
como forma de obtener ingresos económicos, destruyendo y contaminando los territorios sin aportar realmente al buen vivir, ya que la experiencia ha mostrado que el extractivismo no es la solución económica para la superación de la pobreza. En este sentido, la división entre economía y naturaleza es algo que se debe superar para lograr el buen vivir.

Además se plantea que la economía debe medir avances colectivos y no individuales, que permitan ver el adecuado crecimiento en conjunto y no solo de indicadores macro económicos como los actuales. Desde esta perspectiva, el Buen Vivir es entendido como la disminución de la concentración de los medios de producción y las ganancias, así como del fomento de los emprendimientos colectivos a través de la Economía Social y Solidaria, alineados con el respeto a la naturaleza y sus recursos. Por otra parte, el buen vivir debe visibilizar a las formas no monetarias de intercambio que contribuyen al mejoramiento de la calidad de vida de los ciudadanos. Aspectos que no están contemplados en la propuesta de indicadores del gobierno.

En el caso ecuatoriano la concentración de la economía es uno de los problemas graves, sobre todo en el sector alimentario donde mucha de la producción de alimentos para consumo interno y exportación está en manos de pocas empresas (Tabla 3). El sector agroalimentario en pocas manos, como se muestra en la siguiente tabla, sería a manera de ejemplo, uno de los obstáculos que por medio de la redistribución se fortalezca a otros sectores productores de alimentos, sobre todo a los que están en manos de pequeños emprendimientos que ayuden a la desconcentración de este sector.

\section{TABLA 3. Principales sectores de concentración en el Ecuador}

\begin{tabular}{|c|c|c|}
\hline Sector & Controlan el mercado & Resto del mercado \\
\hline Bebidas de todo tipo & $\begin{array}{c}40,92 \% \text { (Cervecería Nacional) } \\
30,41 \% \text { (Arca) }\end{array}$ & $28,67 \%$ (otros) \\
\hline Bebidas no alcohólicas & $81 \%$ (una empresa) & $19 \%$ (155 empresas) \\
\hline $\begin{array}{l}\text { Comerciantes alimenticios agroindustriales } \\
\text { (supermercados) }\end{array}$ & $\begin{array}{c}50 \% \text { (Corporación La Favorita) } \\
31 \% \text { (Corporación El Rosado) } \\
10 \% \text { (Megasantamaría) }\end{array}$ & $9 \%$ (otros) \\
\hline Elaboración de aceite & $92,22 \%$ (dos empresas) & $7,78 \%$ (otras) \\
\hline Carnes & $62,16 \%$ (Pronaca) & $37,84 \%$ (otros) \\
\hline $\begin{array}{l}\text { Elaboración de pastas (macarrones, } \\
\text { fideos...) }\end{array}$ & $54 \%$ (dos empresas) & $29 \%$ (335 empresas) \\
\hline Elaboración de productos de molinería & $71 \%$ (cinco empresas) & $29 \%$ (335 empresas) \\
\hline Elaboración de productos lácteos & $61 \%$ (cinco empresas) & $39 \%$ (436 empresas) \\
\hline $\begin{array}{l}\text { Productos de higiene (jabón, detergente, } \\
\text { perfumes, preparados para limpiar y pulir) }\end{array}$ & $76 \%$ (dos empresas) & $24 \%$ (88 empresas) \\
\hline Fabricación de productos textiles & $61 \%$ (nueve empresas) & $39 \%$ (1 493 empresas) \\
\hline Vehículos & $\begin{array}{c}\text { 72\% (GM- Ómnibus BB) } \\
\text { 17,67\% (Maresa) } \\
\text { 7,62\% (Aymesa) }\end{array}$ & $2,43 \%$ (otros) \\
\hline Electrodomésticos & $\begin{array}{l}85,21 \% \text { (Indurama) } \\
11,49 \% \text { (Fibroscero) }\end{array}$ & $3,30 \%$ (otros) \\
\hline Comunicaciones & $\begin{array}{c}42,15 \%(\text { Conecel }) \\
31,88 \% \text { (Otecel) }\end{array}$ & $25,97 \%$ (otros) \\
\hline
\end{tabular}

Fuente: Martin y Varela (2012). 
En este sentido, para el logro del Buen Vivir sería necesario reducir estos niveles de concentración para generar redistribución, pues crecimiento con concentración es incompatible con los postulados del Buen Vivir.

Como vemos en la tabla anterior, la concentración es sobre todo evidente en el sector de alimentos y bebidas, tanto en la producción como en la distribución. Lo que explica porque es tan importante desde la perspectiva del buen vivir desarrollar mecanismos de desconcentración e incentivos de economía solidaria, para cambiar este aspecto del desarrollo que no genera mejoras en el bienestar ciudadano, y por el contrario las acentúa al no permitir una adecuada redistribución de los recursos existentes.

Por otro lado la medición económica de los impactos que tiene el desarrollo en lo ambiental es sumamente compleja, no existe mediciones de cómo influye esto por ejemplo en el PIB de una nación, ya que simplemente no se toma en cuenta en las mediciones tradicionales. Martínez Alier (2012), considera que el hecho de que la contaminación no le cueste a nadie demuestra como el PIB no es una medida real en la que se pueda ver el desarrollo, y agrega que después de cierto umbral de ingresos no existe relación entre el PIB, satisfacción total y felicidad.

En ese sentido, incorporar como una de las variables principales del buen vivir el efecto de la economía en la naturaleza, resulta ser una propuesta innovadora. Sin embargo, en la propuesta actual de medición que propone el gobierno a través del IPM, nuevamente se excluye la variable de los efectos ambientales para la estimación de las mejoras en la calidad de vida de las personas; sin contar hasta la fecha con datos que nos permitan verificar cuales han sido los costos ambientales del crecimiento económico en el Ecuador.

Desde la teoría, la visión económica del buen vivir apunta también a la reducción de la inequidad en cuanto a la repartición de los recursos productivos, tanto monetarios como no monetarios, que aporten a disminuir la concentración económica, generando mayores oportunidades para los sectores pequeños y medianos, y que estos accedan a recursos para su crecimiento a través de sistemas de economía social y solidaria, así como apoyo directo del Estado en sus emprendimientos.

Asimismo, el reconocimiento de la otra economía, que como ya hemos mencionado más arriba no pasa necesariamente por lo monetario, implica dentro del marco del Buen Vivir su visibilización y apoyo, sobre todo si está contribuye al mejoramiento de la calidad de vida de los territorios donde se practica.

En las áreas rurales con notable presencia indígena y campesina existen relaciones económicas alternativas que están sustentadas en el trabajo colectivo (mingas, intercambios de semillas y alimentos, etc.), y que son parte activa de la construcción del buen vivir en el ámbito rural. Estas relaciones deben ser tomadas en cuenta en las políticas públicas y evaluaciones de sus avances.

Por otro lado, el problema desde una visión económica clásica del desarrollo, es que si en casos como el ecuatoriano por ejemplo, queremos medir el grado de desarrollo por el aumento del PIB, nos tomaría demasiado tiempo en lograr niveles de países considerados "desarrollados" y al mismo tiempo no solucionaría el problema de la concentración de ingresos, como ocurre en casos como el chileno, donde se llega cerca a los niveles de umbral de desarrollo de acuerdo al PIB, pero la concentración e inequidad en la distribución de ingresos es sumamente alta. En la región latinoamericana el índice de GINI es 51,7 en disparidad de ingresos por habitante (CEPAL, 2012), convirtiendo a Latinoamérica en una región con una inequidad preocupante.

El FMI considera que el umbral de desarrollo, de acuerdo al PIB per cápita es de 22.000 USD en paridad de poder adquisitivo (CEPAL, 2012). Este umbral, en el caso ecuatoriano está muy lejos de ser cumplido como podemos ver en la figura 1. Si comparamos los ingresos del Ecuador con los de Chile, el cual es un país que reporta mayores ingresos en la región, vemos que el Ecuador debería por lo menos duplicar sus ingresos por persona, para llegar al nivel de Chile. Al apostar por este indicador como forma de medir el desarrollo, se torna complicado para el Ecuador cumplirlo en los próximos años. 


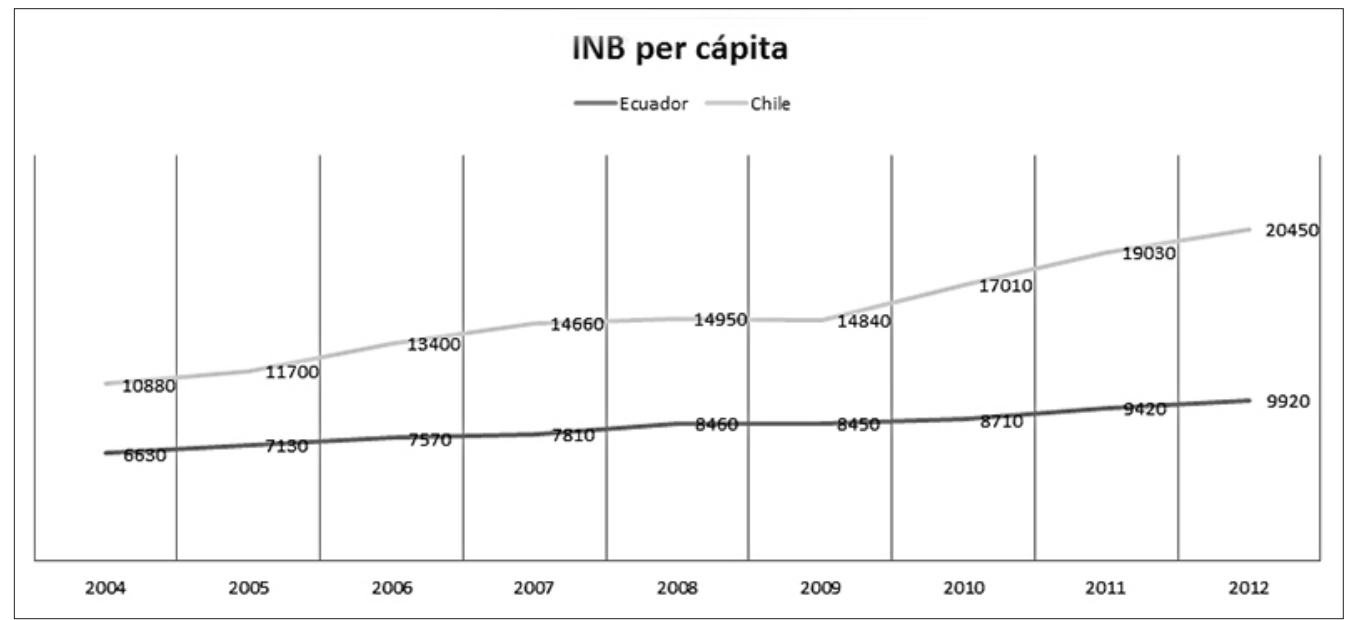

Figura 1. Comparación del Ingreso Nacional Bruto (INB) per cápita entre Ecuador y Chile desde el año 2004 en USD. Elaboración propia con datos tomados del Banco Mundial (2014).

El promedio de crecimiento del INB en el caso ecuatoriano en el periodo 2004-2012 fue de $4,77 \%$, es decir que para llegar al nivel de Chile, que está casi en el umbral de desarrollo, nos tomaría aproximadamente 22 años, y 26 años si quisiéramos llegar al umbral de ingresos que el Banco Mundial considera a un país como desarrollado. Esto coincide con algunos economistas del Buen Vivir, que como hemos mencionado anteriormente, consideran que la medición económica de un país como desarrollado a través del PIB o INB, es una medición que esconde muchas otras realidades sociales como la inequidad, el acceso a servicios como la salud y la educación, y el grado de deterioro ambiental que sufre la naturaleza y los habitantes de un territorio, afectando su calidad de vida.

La economía del Buen Vivir, propone ver al desarrollo económico como un medio, mas no como un fin (Acosta, 2010), centrándose en este aspecto en eliminar la inequidad y la concentración de los ingresos en la economía, así como el desarrollo y reconocimiento de la economía social y solidaria como una forma alternativa de impulso y reconocimiento de las otras formas de intercambio que no necesariamente son monetarias pero que contribuyen a mejorar la calidad de vida de las personas.

Otro aspecto importante, es también el de reconocer desde la economía ecológica el costo que ha tenido sobre la naturaleza y las generaciones futuras el modelo actual de desarrollo, en función de lo cual se puedan tomar las decisiones económicas adecuadas que no comprometan a las generaciones futuras y sus recursos. Esto hace que sea importante incluir estos parámetros en la evaluación de los logros del Buen Vivir.

La economía, según la filosofía del Buen Vivir, es una herramienta del modelo alternativo al desarrollo, donde el objetivo principal no es alcanzar el mejoramiento de los ingresos de las personas a los niveles de los llamados países desarrollados, sino más bien lograr una adecuada y equitativa redistribución de los recursos que permita desarrollar una economía alternativa reconociendo las otras economías que existen en los territorios.

El reto económico en la propuesta del Buen Vivir, estaría en la elaboración de políticas públicas reales que reconozcan e impulsen otras relaciones económicas, así como mejorar la situación de los ciudadanos no desde la vía exclusiva del incremento de sus ingresos sino más bien desde una perspectiva integral de la economía ecológica y humana de las personas. Es decir pasar de la visión económica estatal clásica, a una visión que genere una economía post extractivista desarrollista, a una centrada en el mejoramiento del bienestar y el respeto a la naturaleza. 


\section{La visión del Buen Vivir en el Estado ecuatoriano}

Los Estados que actualmente promueven el Buen Vivir con más fuerza son el ecuatoriano y el boliviano, los cuales lo han incorporado a sus respectivas legislaciones, como se ha mencionado anteriormente.

La visión estatal en el caso ecuatoriano, está contemplada a través de la Constitución en una serie de artículos que están expresados en la Tabla 1, vemos que el Buen Vivir esta en la legislación ecuatoriana como un marco de derechos y objetivo a alcanzar como paradigma de desarrollo en el país.

Para los representantes del Estado ecuatoriano y sus diversas instituciones, el Buen Vivir es acoplado como una serie de derechos y acciones que se deben garantizar, donde los sujetos principales de estos derechos son los seres humanos y la naturaleza (SENPLADES, 2013). Pese a esto, parece haber poca claridad en cuanto a cómo reconocer como sujeto de derechos a la naturaleza, y como el basar la economía en extracción de recursos naturales entra en contraposición con esto.

Desde las instituciones estatales, en el caso ecuatoriano, la idea del Buen Vivir se discute sobre todo a través del Plan Nacional del Buen Vivir (PNBV), el cual en la actualidad está vigente para el período 2013-2017, donde se ha ido dotando a la idea de Buen Vivir de formas para su aplicabilidad en el contexto actual ecuatoriano.

El Buen Vivir desde la visión estatal ecuatoriana, es considerado un modelo alternativo al desarrollo actual que ha promovido el capitalismo y el beneficio de unos pocos que ha permitido acumulación y desigualdad en el país. Para los promotores del Buen Vivir dentro del gobierno actual por ejemplo, es necesario reducir las diferencias económicas y sociales, redistribuyendo los recursos disponibles, pero reconociendo que no basta solamente con redistribuir, sino que al mismo tiempo hay que cambiar las estructuras productivas y de poder existentes (Ramírez, 2012: 26).

En el caso ecuatoriano, se cuenta con varias definiciones y literatura provenientes del gobierno y sus miembros, que dan pautas en el sentido de cómo entender el Buen Vivir, y se delinean una serie de principios y momentos que debe tener la estrategia de desarrollo basada en el Buen Vivir. En cuanto a principios la SENPLADES (2013), plantea que para lograr el Buen Vivir es necesario contar con:

TABLA 4. Principios del Socialismo del Buen ViVIR

\begin{tabular}{|l|l|}
\hline Principios & Características \\
\hline Una sociedad radicalmente justa & $\begin{array}{l}\text { Existencia de justicia social y económica, justicia } \\
\text { democrática y participativa, justicia intergeneracional } \\
\text { (sobre todo enfocada a los impactos ambientales y } \\
\text { sociales para las siguientes generaciones), y justicia } \\
\text { transnacional. }\end{array}$ \\
\hline $\begin{array}{l}\text { Sociedad con trabajo liberador y tiempo } \\
\text { compartido }\end{array}$ & $\begin{array}{l}\text { Donde se apunte a abolir la división sexual del trabajo } \\
\text { f fomentar el uso del tiempo libre en actividades que } \\
\text { permitan la realización plena de las personas. }\end{array}$ \\
\hline Sociedad igualitaria y equitativa & $\begin{array}{l}\text { A través de la distribución y redistribución de recursos, } \\
\text { tanto económicos como sociales. }\end{array}$ \\
\hline $\begin{array}{l}\text { Sociedad con capacidad de emancipación y } \\
\text { autonomía }\end{array}$ & $\begin{array}{l}\text { Enfocado a que los ciudadanos participen activamente } \\
\text { en las decisiones y planes del Estado, así como el } \\
\text { fortalecimiento del Estado como garante de derechos e } \\
\text { impulsor de la participación y mayor poder la sociedad }\end{array}$ \\
\hline
\end{tabular}




\begin{tabular}{|c|c|}
\hline Sociedad Solidaria & $\begin{array}{l}\text { Fomentando la cooperación, solidaridad y fraternidad, } \\
\text { privilegiando el desarrollo colectivo sobre el } \\
\text { desarrollo personal. }\end{array}$ \\
\hline Sociedad corresponsable y propositiva & $\begin{array}{l}\text { Superar que la sociedad solo espere del Estado, } \\
\text { definiéndolo como el equilibrio entre las } \\
\text { responsabilidades del Estado, las instituciones y los } \\
\text { ciudadanos. }\end{array}$ \\
\hline Sociedad en armonía con la naturaleza & $\begin{array}{l}\text { Reconoce los derechos de la naturaleza, poniendo } \\
\text { límites a las actividades que puedan comprometer a las } \\
\text { generaciones futuras. } \\
\text { Plantea también minimizar los impactos ambientales } \\
\text { de las actividades extractivas. } \\
\text { Plantea el bioconocimiento y los valores de los } \\
\text { servicios ecosistémicos como forma de diversificar la } \\
\text { matriz productiva. }\end{array}$ \\
\hline Sociedad de los bienes superiores & $\begin{array}{l}\text { Donde se dé acceso a bienes superiores (los que } \\
\text { garantizan derechos), y que estos deben ser provistos } \\
\text { por el Estado. }\end{array}$ \\
\hline Sociedad de excelencia & $\begin{array}{l}\text { Donde existan esfuerzos individuales y colectivos por } \\
\text { ser cada vez mejores. }\end{array}$ \\
\hline $\begin{array}{l}\text { Sociedad pluralista, participativa y } \\
\text { autodeterminada. }\end{array}$ & $\begin{array}{l}\text { Ciudadanía activa y fortalecimiento de los } \\
\text { movimientos sociales que trabajen coordinadamente } \\
\text { y propongan soluciones a problemas locales y } \\
\text { nacionales. }\end{array}$ \\
\hline Soberanía e integración de los pueblos & $\begin{array}{l}\text { Promover la paz y desarme, así como la ciudadanía } \\
\text { universal. } \\
\text { Impulsar la integración de América del Sur y } \\
\text { Latinoamérica. }\end{array}$ \\
\hline Estado democrático, plurinacional y laico & $\begin{array}{l}\text { Separación clara de las iglesias, proteger la libertad de } \\
\text { conciencia. } \\
\text { Promover toma de decisiones responsables sobre } \\
\text { sexualidad, orientación sexual, etc. Sin discriminación. }\end{array}$ \\
\hline Fortalecimiento de la sociedad & $\begin{array}{l}\text { Sociedad que profundice calidad de la democracia } \\
\text { Empoderar a la sociedad y no al mercado. }\end{array}$ \\
\hline
\end{tabular}

Fuente: SENPLADES (2013).

Toda esta serie de principios, dan cuenta de un amplio avance en la propuesta del Buen Vivir en la planificación y el discurso desde el Estado y sus instituciones. Sin embargo, la declaración de principios y de formas que comienzan la transición hacia el Buen Vivir, pueden no estar siendo aplicadas con la misma eficiencia, sobre todo en los aspectos ambientales, y de Soberanía Alimentaria. Pues, a pesar de que el Plan Nacional del Buen Vivir reconoce a los derechos de la naturaleza y el fortalecimiento de la agroecología para la Soberanía Alimentaria, como principios que ayudan a la construcción del Buen Vivir, en la aplicación de la política pública esto no necesariamente se aplica; o, bien se lo interpreta de diversas formas para justificar las actividades extractivas o el apoyo a la agroindustria para generar recursos, por ejemplo.

Aunque se definen momentos o fases de transición hacia el Buen Vivir, estas fases no hablan de la redistribución y desconcentración de los recursos. Así tenemos que, la primera fase está caracterizada por la dependencia económicamente de recursos primarios y la distribución de 
estos recursos con mayor eficiencia; la segunda fase, estaría dada por el aumento de la actividad industrial y disminución de la actividad primaria, promoviendo actividades como el ecoturismo, la investigación, producción y consumo de energía limpia; la tercera fase, implementaría la diversificación y sustitución de importaciones, en la cual la industria nacional proveería la mayoría de los bienes, obteniendo como resultado, que los ingresos de la industria sean superiores a los de bienes primarios; finalmente, la cuarta fase estaría caracterizada por la generación de bioservicios, bioconocimientos y servicios turísticos, que serán superiores al sector primario en la economía. (Ramírez, 2012: 39-41).

Las fases de transición propuestas por Ramírez, siguen el enfoque clásico del desarrollo, priorizando el aumento de la producción, y la extracción de nuevos servicios de la naturaleza para lograr el crecimiento esperado. Esto se evidencia, por ejemplo, en las políticas aplicadas en lo rural. Donde a partir de este enfoque se privilegian actividades intensivas, y por otro lado existe muy poco apoyo destinado a la Soberanía Alimentaria en manos campesinas.

\section{Buen Vivir y Soberanía Alimentaria. ¿Cuáles son los principales obstáculos?}

La consecución del Buen Vivir, desde lo rural, está muy relacionada con la cosmovisión indígena, ya que ellos como habitantes de los territorios rurales han sido los principales impulsores de este concepto. Los pueblos indígenas han usado este concepto como una forma de explicar su resistencia a modelos que amenazan sus territorios (Hidalgo, 2011).

El Buen Vivir ha sido promovido en relación con el concepto de la Soberanía Alimentaria, el cual fue definido por la Vía Campesina (1996) como:

“...el derecho de cada nación para mantener y desarrollar su propia capacidad para producir los alimentos básicos de los pueblos, respetando la diversidad productiva y cultural. Tenemos el derecho a producir nuestros propios alimentos en nuestro propio territorio de manera autónoma. La Soberanía Alimentaria es una precondición para la seguridad alimentaria genuina"

Organizaciones como la Federación Nacional de Organizaciones Campesinas, Indígenas y Negras (FENOCIN), la Confederación de Nacionalidades Indígenas del Ecuador (CONAIE), y Confederación Kichwa del Ecuador (Ecuarunari), impulsaron la Soberanía Alimentaria en el Ecuador. Este impulso se dio sobre todo porque desde su visión, solo contando con Soberanía Alimentaria se puede conseguir buen vivir. Esto fue plasmado en la Constitución como a continuación podemos leer:

"Otro punto constituyente crucial radica en la Soberanía Alimentaria. Aquí se incorpora la protección del suelo y el uso adecuado del agua, que representa un ejercicio de protección a los millares de campesinos que viven de su trabajo, se transforma en eje conductor de las políticas agrarias e incluso de recuperación del verdadero patrimonio nacional: su biodiversidad" (Acosta, 2010: 21).

Sin embargo, pese al entusiasmo inicial con que se promovió el Buen Vivir y la Soberanía Alimentaria, es preocupante como la concentración de los recursos se mantiene en el campo ecuatoriano. Sobre todo en recursos importantes para la agricultura, como la tierra el agua y las semillas. En este sentido el panorama de concentración sigue siendo particularmente grave, pese a que la propuesta del Buen Vivir fue institucionalizada en el país y pretendía redistribuir y enfocar las políticas agrarias al pequeño campesino, para asegurar que se pueda conseguir su Soberanía Alimentaria como parte del Buen Vivir rural.

En la actualidad por ejemplo, los pequeños productores campesinos que cuentan con extensiones de entre 1 a 5 hectáreas apenas controlan el 7,9\% del total de la superficie agraria del país (Landívar, et al., 2013: 31), mientras que las propiedades con grandes extensiones todavía son recurrentes y están en manos de pocos propietarios individuales o agroindustriales. 
El tema de la concentración de la tierra no ha cambiado significativamente en el país, y por tanto tampoco ha contribuido a la transición hacia el modelo de Soberanía Alimentaria para el Buen Vivir. Hasta finales del año 2011 por ejemplo, solo se entregaron por parte del Estado ecuatoriano 2881 hectáreas de tierra, además de que para el Plan Tierras, solo se habían asignado 4 millones de dólares que corresponden al 2\% del presupuesto total del MAGAP (Ospina, 2011). Es decir, que no ha existido un proceso de redistribución de tierras, y por lo tanto tampoco se ha afectado en mayor medida la alta concentración de este recurso en el país. En este sentido el acceso a la tierra es visto reiteradamente por parte de las organizaciones campesinas e indígenas como uno de los principales temas a resolver para contar con Soberanía Alimentaria que contribuya al Buen Vivir.

\begin{tabular}{|c|c|c|c|c|}
\hline \multirow{2}{*}{\multicolumn{2}{|c|}{ Subsector/Rubro }} & \multicolumn{3}{|c|}{2015} \\
\hline & & $\begin{array}{c}\text { Número } \\
\text { Operaciones }\end{array}$ & $\begin{array}{l}\text { Valor en } \\
\text { dólares }\end{array}$ & Porcentaje \\
\hline \multicolumn{2}{|c|}{ Total crédito original } & 64.010 & 255.689 .121 & \\
\hline \multirow{15}{*}{ Agrícola } & Cacao & 3.828 & 15.958 .955 & $6,24 \%$ \\
\hline & Maíz & 6.254 & 10.020 .997 & $3,92 \%$ \\
\hline & Arroz & 2.637 & 8.478 .435 & $3,32 \%$ \\
\hline & Palma Africana & 201 & 4.304 .386 & $1,68 \%$ \\
\hline & Café & 973 & 3.962 .722 & $1,55 \%$ \\
\hline & Papa & 870 & 2.409 .089 & $0,94 \%$ \\
\hline & Caña de Azúcar & 134 & 1.071 .210 & $0,42 \%$ \\
\hline & Banano & 35 & 578.362 & $0,23 \%$ \\
\hline & Cebolla & 220 & 512.645 & $0,20 \%$ \\
\hline & Tomate Hortícola & 82 & 398.888 & $0,16 \%$ \\
\hline & Fréjol & 140 & 187.822 & $0,07 \%$ \\
\hline & Soya & 33 & 34.186 & $0,01 \%$ \\
\hline & Arveja & 13 & 24.202 & $0,01 \%$ \\
\hline & Trigo & 6 & 18.777 & $0,01 \%$ \\
\hline & Otros Cultivos & 3.914 & 17.572 .873 & $6,87 \%$ \\
\hline \multirow{5}{*}{ Pecuario } & Ganado Bovino & 23.337 & 114.028 .415 & $44,60 \%$ \\
\hline & Ganado Porcino & 10.665 & 27.024 .718 & $10,57 \%$ \\
\hline & Avicultura & 4.208 & 6.083 .163 & $2,38 \%$ \\
\hline & Otros Ganados & 1.794 & 2.788 .329 & $1,09 \%$ \\
\hline & Pastos & 110 & 823.555 & $0,32 \%$ \\
\hline Pesca & Pesca & 605 & 2.404 .873 & $0,94 \%$ \\
\hline \multirow{3}{*}{ Varios } & Mejoras Territoriales & 3.090 & 27.524 .212 & $10,76 \%$ \\
\hline & Maquinaria Agrícola & 665 & 7.325 .156 & $2,86 \%$ \\
\hline & Movilización de Productos & 196 & 2.153 .150 & $0,84 \%$ \\
\hline
\end{tabular}


En el caso de la tierra, las políticas agrarias no se encuentran en sintonía con las leyes y la Constitución del Ecuador, y por el contrario siguen privilegiando a las actividades que favorecen la concentración, a través, por ejemplo, de préstamos estatales que se dan a actividades que acaparan tierra, como la ganadería bovina que en el año 2015 acaparó el 45\% del total de los préstamos otorgados por el Banco Nacional de Fomento (BNF).

La tabla anterior, nos muestra asimismo que el impulso a través del crédito que tienen los productos para alimentación en manos campesinas, tales como el tomate, la cebolla o la arveja, no supera el $1 \%$ de todo el crédito concedido por el Banco Nacional de Fomento. Lo cual no promueve la diversificación y desconcentración de este sector productivo, que podría mejorar las condiciones de vida de pequeños campesinos.

En cuanto a riego, el panorama es igualmente preocupante. En la figura 2, podemos ver como las Unidades de Producción Agraria (UPAs), que cuentan con más de 100 ha., concentran el $40,74 \%$ del total del agua para el riego disponible, en comparación de las UPAs de menos de 10 $\mathrm{Ha}$, que acceden a apenas el $25 \%$ del total del agua para riego, de acuerdo a los datos del Censo Nacional Agropecuario del 2000. Pese a que no existen datos más actualizados, la mayoría de investigadores coinciden que la concentración en cuanto a este recurso no se ha modificado sustancialmente en la actualidad.

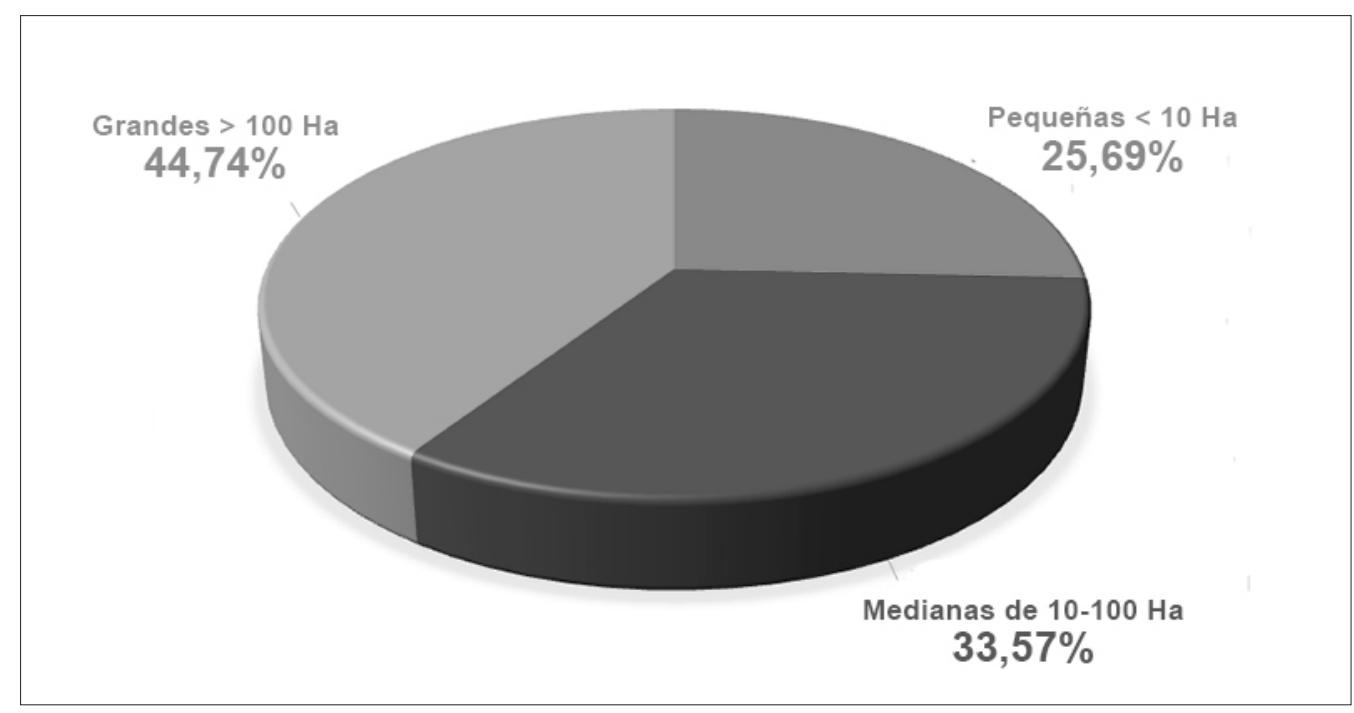

Figura 2. Superficie regada de acuerdo al tamaño de la UPA. Fuente: III Censo nacional agropecuario (2000) Y AQUASTAT (2016)

La concentración del agua para riego es uno de los problemas más graves en el país, puesto que la "mayor parte del agua de fácil acceso para riego ya se encuentra concesionada" (Gaybor, 2010: 57). Esto torna difícil emprender una redistribución de este recurso, sin una decisión política clara al respecto, que contribuya a generar el Buen Vivir en los territorios rurales y al mismo tiempo promueva la Soberanía Alimentaria.

Las semillas para la agricultura, tienden igualmente a estar dominadas en ciertos cultivos, por unas pocas empresas que controlan su distribución y comercialización. Por ejemplo, en maíz, arroz y soya, tres empresas concentren el 90\% del mercado (AGRIPAC, Ecuaquímica y PRONACA). En el caso de las hortalizas, AGRIPAC maneja el 25\%, Ecuaquímica el 10\% y PRONACA el 5\%. (León y Yumbla, 2010), sin hasta la actualidad contar con un programa que permita desconcentrar el control de estas semillas, ya que las políticas públicas no apuntan a mejorar el acceso y la distribución de semillas locales. Promoviendo, por ejemplo, el mejoramiento participativo entre 
campesinos y el Instituto Nacional Autónomo de Investigaciones Agropecuarias (INIAP), que permitan depender menos de estas semillas siguiendo los principios de la Soberanía Alimentaria y el Buen Vivir.

\section{Conclusiones}

A partir de la inclusión del Buen Vivir en la Constitución ecuatoriana han existido pocos avances en cuanto a la forma de aplicarlo como una alternativa integral de desarrollo, que ayude a su consolidación en todas las dimensiones contempladas.

El reconocimiento del paradigma del Buen Vivir, lastimosamente no ha contribuido en mayor medida a mejorar las condiciones de vida de los sectores rurales, puesto que no ha sido acompañado de políticas públicas diferenciadas que fomenten una redistribución adecuada de todos los recursos, que permitan que los pobladores rurales mejoren sus condiciones de vida de acuerdo a los planteamientos del Buen Vivir.

Por otro lado, para poder medir los avances del Buen Vivir, uno de los principales retos, es el contar con un sistema de indicadores claros que permitan evaluar los progresos en la consecución del mismo, incluyendo todos los derechos contemplados en la Constitución ecuatoriana.

Otras alternativas al desarrollo ya han logrado contar con indicadores consensuados, que les permiten medir otros avances en el mejoramiento de la calidad de vida de los ciudadanos, que no pasen solo por los indicadores clásicos económicos. Sin embargo, en el caso del Buen Vivir, todavía hace falta contar con elementos diferenciadores que aporten a evaluar avances reales en el bienestar de los ciudadanos bajo este paradigma. Como por ejemplo, la inclusión de la Soberanía Alimentaria, los derechos de la naturaleza, el acceso a los recursos productivos, entre otros, que ya se contemplan en la Constitución, pero que no se evalúan en la política pública ecuatoriana.

La elaboración de indicadores, debería contemplar un proceso participativo, que permita generar herramientas de medición consensuadas entre los ciudadanos, y no solamente entre los técnicos estatales.

Por otro lado, en lo rural es necesario que se tome en cuenta los efectos que está teniendo la consolidación del sistema agroalimentario basado en el agronegocio y la gran agroindustria, que han generado la reconcentración de los recursos necesarios para la agricultura, como el agua, la tierra, el crédito y las semillas. Lo que no ha permitido que se desarrolle el régimen alternativo de producción de alimentos basado en la agricultura campesina y la Soberanía Alimentaria como se contempla en el art. 281 de la Constitución.

Pese al reconocimiento del derecho a la Soberanía Alimentaria como parte de la propuesta de Buen Vivir, no se ha logrado todavía que se genere un sistema agroalimentario basado en este derecho. La desconexión entre los derechos del Buen Vivir y las políticas públicas en lo rural, provoca que se privilegie a través de créditos, actividades que son manejados por medianos y grandes productores, quedando el pequeño campesino, que puede producir para el mercado local y aportar a la construcción de la Soberanía Alimentaria, fuera de estas políticas.

Mientras no se consideren aspectos como estos, lastimosamente el Buen Vivir podría quedar indefinidamente como un concepto en discusión, y no como una propuesta consolidada. El principal problema que puede observarse en este sentido en lo rural, es el poco apoyo que están recibiendo los sujetos clave para la construcción del Buen Vivir y la Soberanía Alimentaria, que son los campesinos del país. Tampoco se ve un gran esfuerzo por generar acciones, que permitan que la naturaleza sea otro de los sujetos de derecho clave para la consecución del Buen Vivir.

Finalmente, podríamos concluir que la adopción del paradigma del Buen Vivir en la Constitución ecuatoriana, cuenta con ciertos logros en cuanto al reconocimiento de derechos y disminución de pobreza, pero que hace falta todavía mucha más claridad en cuanto a la forma de lograr mejorar el bienestar de los ciudadanos. Especialmente en lo rural, en cuanto al acceso a 
los derechos a la Soberanía Alimentaria y a la naturaleza. Debido a que se cuenta con muy pocas políticas públicas, que contribuyan específicamente a garantizar estos derechos, y por otro lado, a que la propuesta de indicadores actuales todavía es insuficiente para evaluar el acceso a los derechos que tienen que ver con el Buen Vivir rural.

\section{Bibliografía}

Acosta, Alberto. 2010, "El Buen Vivir en el camino del post-desarrollo. Una lectura desde la Constitución de Montecristi”, en: Policy paper 9, Fundación Friedrich Ebert, FES-ILDIS, Quito.

Acosta, Alberto y Martínez, Esperanza (Comp.) 2009, El buen vivir: una vía para el desarrollo, Abya-Yala, Quito, 2009.

AQUASTAT. 2016, “Agua en Ecuador”. FAO. Disponible en: http://www.fao.org/nr/water/aquastat/countries regions/ecu/indexesp.stm (27.03.2017).

Castillo, Roberto y Jácome, Fausto. 2016, “Medición de la Pobreza Multidimensional en Ecuador”, INEC. Quito, disponible en: http://www.ecuadorencifras.gob.ec/documentos/web-inec/Sitios/Pobreza_Multidimensional/ assets/ipm-metodologia-oficial.pdf (27.03.2017).

CEPAL. 2012, "Eslabones de la desigualdad. Heterogeneidad estructural, empleo y protección social”, Comisión Económica para América Latina y el Caribe (CEPAL), Santiago de Chile.

Constitución Política del Ecuador. 2008, Asamblea Nacional Constituyente. Montecristi -Ecuador.

Correa, Rafael. 2016, "lanzamiento del índice de pobreza multidimensional", disponible en: http://www. presidencia.gob.ec/wp-content/uploads/downloads/2016/02/INDICE-DE-LA-POBREZA.pdf (27.03.2017).

Gaybor, Antonio. 2010, "Acumulación capitalista en el campo y despojo del agua", en: Acosta, Alberto y Martínez, Esperanza, Agua. Un derecho humano fundamental, Abya-Yala, Quito, 47-66.

Gudynas, Eduardo. 2011, "Buen Vivir: Germinando alternativas al desarrollo", en: América Latina en Movimiento, 153, pp.1-20.

Gudynas, Eduardo y Acosta, Alberto. 2011, "La renovación de la crítica al desarrollo y el buen vivir como alternativa", en: Utopía y praxis latinoamericana, $\mathrm{N}^{\circ} 53$ (16), 71-83.

Hidalgo-Capitán, A. et al., 2014. "El pensamiento indigenista ecuatoriano sobre el Sumak Kawsay", en: Hidalgo Capitán, A. et al. (Eds.) Antología del Pensamiento Indigenista Ecuatoriano sobre Sumak Kawsay, CIM y PYDLOS, Huelva y Cuenca, pp: 23-73.

Hidalgo, Francisco. 2011, “Tierra: Soberanía Alimentaria y Buen Vivir”, en: La línea de fuego, disponible, en: http://lalineadefuego.info/2011/10/14/tierra-soberania-alimentaria-y-buen-vivir-por-francisco-hidalgo/ (27.03.2017).

INEC. 2015. "Encuesta Nacional de Empleo, Desempleo y Subempleo Indicadores de Pobreza y Desigualdad". Disponible en: http://www.ecuadorencifras.gob.ec/documentos/web-inec/POBREZA/2015/Diciembre_2015/ Presentacion_pobreza_y_desigualdad_dic_15.pdf (27.03.2017).

2000, III Censo nacional agropecuario, Quito- Ecuador.

Landívar, Natalia et al. 2013, Monitoreo de Políticas de Tierra y el Derecho a la Alimentación en Ecuador, Informe 2013, FIAN-Ecuador.

León, Xavier y Yumbla, María Rosa. 2010, El agronegocio en Ecuador: El caso del Maíz, Acción Ecológica, Quito.

MAGAP. 2015, "Estadísticas de créditos concedidos", disponible en: http://sinagap.agricultura.gob.ec/index. $\mathrm{php} /$ banecuador/nacional/2016/file/2722-comparaci\%C3\%B3n-per\%C3\%ADodo-acumulado-diciembrea\%C3\%B1os-2010-2015-2016 (27.03.2017).

Martín, Fernando y Varela, Marcelo. 2012, "Hacia una mayor concentración de los grupos económicos del Ecuador•", en: Revista Ekos, 12, Quito. Disponible en: http://www.ekosnegocios.com/negocios/m/ verArticulo.aspx?idArt=355 (23.03.2017).

Martínez Alier, Joan. 2012, "Economía ecológica y justicia ambiental", en: La línea de fuego, disponible en: http://lalineadefuego.info/2012/07/18/economia-ecologica-y-justicia-ambiental1-por-joan-martinez-alier/ (24.03.2017)

Martínez, Esperanza. 2011, "Prologo", en: Acosta, Alberto y Esperanza, Martínez (Comp.) La naturaleza con derechos. De la filosofía a la política, Abya- Yala, Quito. 
ONU. 2015, "Índice de Desarrollo Humano". Disponible en: http://hdr.undp.org/es/content/el-\%C3\%ADndicede-desarrollo-humano-idh (24.03.2017).

Ospina, Pablo. 2011, "La redistribución agraria en la revolución ciudadana", en: La línea de fuego, Disponible en: http://lalineadefuego.info/2011/06/30/la-redistribucion-agraria-en-la-revolucion-ciudadana-segunda-parte/ (09.03.2017)

Phélan, M. et al. 2012, "Sistematización de índices e indicadores alternativos de desarrollo para América Latina", en: Revista temas de coyuntura, (66).

Phélan, Mauricio. 2011, "Revisión de índices e indicadores de desarrollo. Aportes para la medición del buen vivir (sumak kawsay)", en: Revista de Ciencias Sociales. (6) 1. 69-95.

Ponce, Juan y Acosta, Alberto. 2010, “La pobreza en la revolución ciudadana o ¿pobreza de revolución?”, en: Ecuador Debate. Cultura y política, N81, Centro Andino de Acción Popular CAAP, Flacso, Ecuador.

Presidencia de la República. 2008, "El Mandato Agrícola", en: http://www.sri.gob.ec/BibliotecaPortlet/ descargar/127be933-4a7d-40be-906d-3cee4d7d546c/Mandato+No.16.doc (27.03.2017).

Pringle, P. 2003, Food, inc: Mendel to Monsanto--the promises and perils of the biotech harvest, Simon and Schuster.

Ramírez, René. 2012, Socialismo del Sumak Kawsay o bio-socialismo republicano, Secretaría Nacional de Educación Superior, Ciencia, Tecnología e Innovación, Quito.

Recasens, A. V. 2014, "Discursos" pachamamistas" versus políticas desarrollistas: el debate sobre el sumak kawsay en los Andes", en: Íconos-Revista de Ciencias Sociales, (48), Quito, pp. 55-72.

Rosset, Peter. 2007, "Mirando hacia el futuro: La Reforma Agraria y la Soberanía Alimentaria", en: AREAS, Revista Internacional de Ciencias Sociales, № 26.

2003, "Food Sovereignty: Global Rallying Cry of Farmer Movements", Institute for Food and Development Policy Backgrounder vol. 9, N. 4, disponible en: https://foodfirst.org/wp-content/uploads/2013/12/BK9_4Fall-2003-Vol-9-4-Food-Sovereignty.pdf

1998, "La crisis de la agricultura convencional, la sustitución de insumos y el enfoque agroecológico", Food First, Institute for Food and Development Policy, Oakland, disponible en: https://foodfirst.org/wp-content/ uploads/2013/12/PB3-La-Crisis-de-la-Agricultura-Convencional.pdf

Sánchez Parga, J. 2011, "Discursos retrovolucionarios: sumak kawsay, derechos de la naturaleza y otros pachamamismos", en: Ecuador Debate, N 84, Quito, pp 31-50.

SENPLADES. 2013, Plan Nacional para el Buen Vivir 2013-2017: Construyendo un Estado Plurinacional e Intercultural, Secretaría Nacional de Planificación y Desarrollo, Quito.

2009 Estrategia para el buen vivir rural, Secretaría Nacional de Planificación y Desarrollo, Quito- Ecuador.

Sevilla Guzmán, E. 2006, "Agroecología y agricultura ecológica: hacia una "re” construcción de la Soberanía Alimentaria", en: Agroecología, (1), pp. 7-18.

SIPAE. 2011, Atlas sobre la tenencia de la tierra en el Ecuador, Quito.

Soberanía Alimentaria. 2013, "Soberanía Alimentaria y Economía Solidaria son inseparables", en: Revista Soberanía Alimentaria; Biodiversidad y Culturas, GRAIN. 12, Barcelona.

SRI. 2015, "Grupos Económicos". Servicio de Rentas Internas Ecuador. Disponible en: http://www.sri.gob.ec/ de/335 (27.03.2017).

Stefanoni, P. 2011, “AAdónde nos lleva el pachamamismo?”, en: Tabula Rasa-Revista de Humanidades, № 15, Bogotá, pp. 261-264.

Tortosa, José María. 2011, “Sumak kawsay, suma qamaña, buen vivir”, en: Aportes Andinos, № 28, Universidad Andina Simón Bolívar, Sede Ecuador Programa Andino de Derechos Humanos. 3, Quito.

2009, "Sumak kawsay, suma qamaña, buen vivir", Fundación Carolina, España, disponible en: http://www. rebelion.org/noticia.php?id=90660 .

UNDP. 2013, El PNUD destaca indice de desarrollo humano 'alto' de Ecuador, disponible en: http://data.undp. org/resource/efc4-gjvq.json (09.03.2017)

Vía Campesina. 2011, "La agricultura campesina sostenible puede alimentar al mundo", en: Documento de Punto de Vista de la Via Campesina, Yakarta.

1996, Food Sovereignty: A Future Without Hunger. La Via Campesina's 1996 Statement by the NGO Forum to the World Food Summit, NGO Forum to the World Summit, disponible en: http://www.acordinternational.org/ silo/files/decfoodsov1996.pdf (27.03.2017)

Vicepresidencia República del Ecuador. 2015, Estrategia nacional para el cambio de la matriz productiva, Quito. Viteri Gualinga, C. 2003, Súmak Káusai. Una respuesta viable al desarrollo, Tesis de Licenciatura en Antropología Aplicada, Universidad Politécnica Salesiana del Ecuador, Quito. 